\title{
Development of Contemporary Kathiawar Embroidery Designs for Jacket
}

\author{
Pooja*, Vivek Singh and Nisha Arya \\ Department of Textile \& Apparel Designing, COHS, CCS HAU, Hisar, Haryana, India \\ *Corresponding author
}

Keywords

Designs, Kathiawar, Embroidery, Fabric painting

\section{Article Info}

Accepted:

15 January 2019

Available Online:

10 February 2019

\section{A B S T R A C T}

Revival of traditional embroidery painting is considered as an important aspect in present scenario. A study was conducted to explore the possibility of adaptation of kathiawar embroidery motifs for fabric painting. Seventy collected kathiawar embroidery motifs were categorized as geometrical, floral and animal \& bird motifs and were screened into thirty motifs keeping in mind their suitability for fabric painting on jacket. These three categories included ten motifs each. Thus, a total of thirty motifs were finalized for further research work. The selected motifs were scanned to convert them from print version to digital format and edited with the help of Corel DRAW software. The proportion of motifs was changed to make them suitable for fabric painting on jacket. Selected motifs were got evaluated from thirty experts. A total of twelve motifs including four top ranked motifs from each category i.e. geometrical, floral and animal \& bird motifs were selected by experts to create twenty designs for each motif. A total of sixty designs were created using total twelve selected motifs with the help of CorelDraw software. This can open the avenues for the designers especially for those who create kathiawar inspired clothing to display on global platform. This study will cater the demands of high-end consumers through diversity of designs and unique technique of fabric painting.

\section{Introduction}

India is a land of rich traditions and diverse culture it has one of the finest textile traditions in the world with respect to fabric construction and surface embellishment. Embroidery is one of the oldest and beautiful ways of surface embellishment. Each type of embroidery serves its purpose in adding richness and value to the article it adorns. It may also be ornamented with other materials such as beads, pearls, stones and mirrors. Embroidery is one of the most satisfying and interesting art which is gaining more and more popularity day by day as it requires minimum equipments and space (Kaur, 2015). Embroidery is the art of decorating the fabric using stitches as a decorative feature. It forms an art style of beautiful drawing, harmonious color, sprightly line and elaborate needle skill. It is an expression of self, rendered with patience, brilliance and dedicated hard work. The origin of Indian textiles can be traced to the Indus valley civilization. The art of embroidery is clearly of the Eastern origin and is of such ancient lineage that our knowledge of it stretches into pre-historic ages (Garg, 2016). 
Indian embroideries are ethnic, simple and colorful, and yet vibrant enough to speak volumes about its rich heritage. India is a multifaceted cultural land with each region having a distinctive style of its own, adding variety and richness to this craft. The range of Indian embroidery style is closely linked to the regional variation. The regional and cultural diversity of regions can be easily noticed in their unique styles through the peculiar types of threads, colors and motifs related to nature, religion and everyday life of people-representing the culture and lifestyle of their community. Indian embroidery, both domestic and professional almost from every state of India has its specific traditional charm. Each state in India is unique by itself as far as embroidery and its variegated designs are concerned. Today all over India classic embroideries are practiced by different castes and classes viz., kantha of Bengal, kasida of Bihar, kutch and kathiawar of Gujrat, chamba rumal of Himachal Pradesh, kasuti of Karnataka, kashida of Kashmir, embroidery of manipuri, applique craft of Orissa, phulkari of Punjab, chikankari of Uttar Pradesh and embroidery of Rajasthan (Byadgi and Naik, 2010).

Embroidery has been a passion in the state of Gujarat. The state is famous for the embroidery of kutch and kathiawar. Kathiawar embroidery has a great influence of neighboring states and places like Sindh, Punjab and Kutch. Kathiawar and sind embroideries are almost identical and have much in common. Kathiawar embroidery is one of the marked techniques of surface embellishment of Kathiawar district of Gujarat state. Here the embroideries of different techniques and styles are noticeable. The embroidery is colorful, elaborate and lavishly done on the choli and ghagharas which is the traditional costume of kathiawar. Sparking mirrors enhance the stunning beauty of the floral and figurative designs in vibrant colour contrasts. Kathiawar women not only beautified their traditional costume by embroidering in vivid colours but also prepared household articles like Toran and Chakla. The main feature of kathiawar embroidery is the lavish application of mirrors along with chain stitch, darning stitch, herringbone stitch and interlacing stitch or sindhi tropa (Acharya, 2017).

\section{Materials and Methods}

The present study was conducted in Hisar district of Haryana state. A total of seventy motifs were collected from secondary sources like books, magazines, journals and internet. These motifs were categorized and screened into thirty motifs by advisory committee keeping in mind their suitability for fabric painting on jacket. These three categories included ten motifs each. Thus, a total of thirty motifs were finalized for further research work. Thirty motifs were got assessed by a panel of thirty experts comprising faculty members and PG students from I. C. College of Home Sciences, CCS Haryana Agricultural University, Hisar with the help of developed preferential index. The experts were asked to give their preferences for each motif separately in different categories for its suitability to fabric painting on jacket.

Their preferences were taken on three point continuum scale as highly preferred, preferred and least preferred. The weighted mean score of each motif was calculated to give ranks in different categories. A total of twelve motifs included four top ranked motifs from each category i.e. geometrical, floral and animal \& bird motifs were selected to create designs.

Twelve selected motifs i.e. four top ranked motifs from each category were used to develop compound designs. Designs were created on the basis of their suitability for 
fabric painting on jacket with the help of Corel DRAW. Each motif was converted into five designs by combining two or three motifs / parts of motifs. Hence, a total of sixty designs were created. The created designs were got assessed by a panel of experts with the help of developed preferential choice index. Five top ranked designs were selected for preparation of design placements on jacket.

\section{Results and Discussion}

The data regarding preferences of experts presented in Table 1 revealed that motif number G1 amongst geometrical motifs with

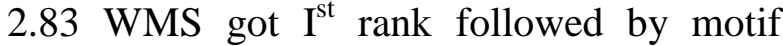
number G8 with 2.70 WMS got II $^{\text {nd }}$ rank, motif number G9 with 2.66 WMS got III ${ }^{\text {rd }}$ rank and motif number $\mathrm{G} 2$ with $2.63 \mathrm{WMS}$ got $\mathrm{IV}^{\text {th }}$ rank. The other motifs upto IX ${ }^{\text {th }}$ rank in descending order were motif number G5(2.50), G4(2.40), G6(2.06), G3(1.90) and G10(1.86). The geometrical motif number G7 was the least preferred motif with $1.13 \mathrm{WMS}$ got $\mathrm{X}^{\text {th }}$ rank.

Motif number F9 amongst floral motifs with 2.93 WMS got $\mathrm{I}^{\text {st }}$ rank followed by motif number F5 with 2.73 WMS got II $^{\text {nd }}$ rank, motif number F8 with 2.66 WMS got III $^{\text {rd }}$ rank and motif number F4 with $2.60 \mathrm{WMS}$ got $\mathrm{IV}^{\text {th }}$ rank. The other motifs upto IX ${ }^{\text {th }}$ rank in descending order were motif number F7(2.56), F1(2.50), F6(2.46), F3(2.33) and $\mathrm{F} 10(2.30)$. The floral motif number F2 with 2.26 WMS got $\mathrm{X}^{\text {th }}$ rank.

Motif number AB1 amongst animal and bird motifs with 2.86 WMS got $\mathrm{I}^{\text {st }}$ rank followed by motif number AB5 with 2.56 WMS got II $^{\text {nd }}$ rank, motif number $\mathrm{AB} 3$ got III $^{\text {rd }}$ rank with WMS 2.53 and motif number AB7 got $\mathrm{IV}^{\text {th }}$ rank with WMS 2.50. The other motifs upto $\mathrm{IX}^{\text {th }}$ rank in descending order were motif number $\mathrm{AB} 4(2.43), \mathrm{AB} 6(2.40), \mathrm{AB} 2(2.33)$,
$\mathrm{AB} 8(2.30)$ and $\mathrm{AB} 10(2.23)$. The motif number AB9 with 2.16 WMS got $\mathrm{X}^{\text {th }}$ rank.

It is thus inferred that motif number G1,G8, G9 and G2 as geometrical motifs, motif number F9, F5, F8 and F4 as floral motifs and motif number $\mathrm{AB} 1, \mathrm{AB} 5, \mathrm{AB} 3$ and $\mathrm{AB} 7$ as animal and bird motifs, with $\mathrm{I}^{\text {st }}, \mathrm{II}^{\text {nd }}, \mathrm{III}^{\text {rd }}$ and $\mathrm{IV}^{\text {th }}$ ranks respectively in each respective category were selected for creation of designs. Kaur (2015) observed that floral motifs were the most preferred embroidery motifs with score 102. Second preference was given to geometrical motifs (92) and third preferred motifs were bird motifs with score 76 .

The data regarding preferences of experts presented in Table 2 revealed that each selected motif was used to create five compound designs by combining two or three motifs. No limitation was kept regarding type and number of motifs in single design. Thus, a total of sixty designs were created and were numbered from 1 to 60 . The data revealed that design number 13 with 2.99 WMS got $\mathrm{I}^{\text {st }}$ rank, followed by design number 21 got II $^{\text {nd }}$ rank with 2.96 WMS, design number 45 with 2.95 WMS got III $^{\text {rd }}$ rank, design number 3 with 2.73 WMS got IV $^{\text {th }}$ rank and design number 46 with 2.70 WMS got $\mathrm{V}^{\text {th }}$ rank. The other designs upto LIX rank in descending order were design number 56(2.66), 60(2.63), 23(2.60), 6(2.53), 50 and 14(2.46), 5(2.43), 51(2.40), 25(2.36), 41(2.33), 37(2.30), 8(2.26), 31(2.23), 19(2.20), 22(2.16), 59(2.13), 12 (2.10), 1and 42(2.06), 39 and $52(2.00), 33(1.96), 2,36$ and 40(1.93), 30(1.90), 11 and 58(1.86), 20(1.83), 38(1.80), 43 and 44(1.76), 7 and 29(1.73), 57(1.70), 9(1.66), 48(1.63), 18 and 34(1.60), 53(1.56), 24(1.53), 17(1.50), 26(1.46), 15 and 47(1.40), 55(1.36), 16 and 27(1.33), 28(1.30), 49(1.26), 4 (1.20), 32 (1.16), 10(1.13), 54(1.1). The least preferred design was design number 35with 1.03 WMS and got LX rank. 
Table.1 Preferences of experts for kathiawar embroidery motifs for jacket

\begin{tabular}{|c|c|c|c|}
\hline $\begin{array}{l}\text { Sr. No. and } \\
\text { Category }\end{array}$ & Motifs & WMS & Rank \\
\hline \multicolumn{4}{|c|}{ Geometrical Motifs } \\
\hline G1 & $\begin{array}{l}\square \square \\
\square \square\end{array}$ & 2.83 & I \\
\hline G2 & & 2.63 & IV \\
\hline G3 & & 1.90 & VIII \\
\hline G4 & & 2.40 & VI \\
\hline G5 & & 2.50 & V \\
\hline G6 & & 2.06 & VII \\
\hline G7 & & 1.13 & $X$ \\
\hline G8 & & 2.70 & II \\
\hline G9 & & 2.66 & III \\
\hline G10 & & 1.86 & IX \\
\hline \multicolumn{4}{|l|}{ Floral Motifs } \\
\hline F1 & & 2.50 & VI \\
\hline $\mathbf{F 2}$ & & 2.26 & $X$ \\
\hline F3 & & 2.33 & VIII \\
\hline F4 & & 2.60 & IV \\
\hline F5 & and & 2.73 & II \\
\hline
\end{tabular}




\begin{tabular}{|c|c|c|c|}
\hline F6 & త్ర్రక & 2.46 & VII \\
\hline F7 & & 2.56 & $\mathrm{~V}$ \\
\hline F8 & & 2.66 & III \\
\hline F9 & & 2.93 & $\mathbf{I}$ \\
\hline F10 & & 2.3 & IX \\
\hline \multicolumn{4}{|c|}{ Animal \& Birds Motifs } \\
\hline AB1 & & 2.86 & $\mathbf{I}$ \\
\hline AB2 & & 2.33 & VII \\
\hline AB3 & & 2.53 & III \\
\hline AB4 & & 2.43 & $\mathrm{~V}$ \\
\hline AB5 & & 2.56 & II \\
\hline AB 6 & 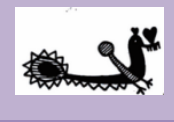 & 2.40 & VI \\
\hline AB7 & & 2.50 & IV \\
\hline AB8 & & 2.30 & VIII \\
\hline AB 9 & 208) & 2.16 & $X$ \\
\hline AB10 & & 2.23 & IX \\
\hline
\end{tabular}


Table.2 Preferences of experts for created designs

\begin{tabular}{|c|c|c|c|c|c|c|c|}
\hline $\begin{array}{c}\text { Number } \\
\text { of } \\
\text { Selected } \\
\text { motifs }\end{array}$ & $\begin{array}{c}\text { Created design } \\
\text { number (Motif / } \\
\text { Parts of motif } \\
\text { no. used) }\end{array}$ & WMS & Ranks & $\begin{array}{c}\text { Number } \\
\text { of } \\
\text { Selected } \\
\text { motifs }\end{array}$ & $\begin{array}{l}\text { Created design } \\
\text { number (Motif / } \\
\text { Parts of motifs } \\
\text { no. used) }\end{array}$ & WMS & Ranks \\
\hline \multirow[t]{5}{*}{ G1 } & $1(\mathrm{G} 1, \mathrm{~F} 4)$ & 2.06 & XXIV & F8 & 31(F8,G1) & 2.23 & XVIII \\
\hline & $2(\mathrm{G} 1, \mathrm{~F} 2)$ & 1.93 & $\mathrm{XXX}$ & & 32(F8,F2) & 1.16 & LVII \\
\hline & 3(G1F8) & 2.73 & IV & & $33(\mathrm{~F} 8, \mathrm{G} 7)$ & 1.96 & XXVII \\
\hline & 4(G1,G9) & 1.20 & LVI & & 34(F8,G7) & 1.60 & XLIII \\
\hline & $5(\mathrm{G} 1, \mathrm{~F} 3, \mathrm{~F} 8)$ & 2.43 & XII & & $35(\mathrm{~F} 8, \mathrm{~F} 2)$ & 1.03 & LX \\
\hline \multirow[t]{5}{*}{ G8 } & $6(\mathrm{G} 8, \mathrm{G} 4)$ & 2.53 & IX & $\mathrm{F} 4$ & 36(F4,F9) & 1.93 & XXIX \\
\hline & $7(\mathrm{G} 8, \mathrm{G} 4)$ & 1.73 & XXXIX & & $37(\mathrm{~F} 4, \mathrm{~F} 9)$ & 2.30 & XVI \\
\hline & 8(G8,G4,G9) & 2.26 & XVII & & $38(\mathrm{~F} 4, \mathrm{G} 8)$ & 1.80 & XXXV \\
\hline & $9(\mathrm{G} 8, \mathrm{G} 4)$ & 1.66 & XLI & & $39(\mathrm{~F} 4, \mathrm{AB} 5)$ & 2.00 & XXVI \\
\hline & $10(\mathrm{G} 8, \mathrm{G} 4)$ & 1.13 & LVIII & & 40(F4,G9) & 1.93 & XXVIII \\
\hline \multirow[t]{5}{*}{ G9 } & 11(G9.F9) & 1.86 & XXIII & $\mathrm{AB} 1$ & 41(AB1,F8,F2) & 2.33 & $\mathrm{XV}$ \\
\hline & $12(\mathrm{G} 9, \mathrm{G} 3)$ & 2.10 & XXII & & 42(AB1,F8,F2) & 2.06 & XXIII \\
\hline & 13(G9,G1) & 2.93 & I & & 43(AB1,G10,F7) & 1.76 & XXXVII \\
\hline & 14(G9,G1,F9) & 2.46 & $\mathrm{X}$ & & 44(AB1,G1,F9) & 1.76 & XXXVI \\
\hline & 15(G9G3G1) & 1.40 & XLIX & & 45(AB1,F8,F2) & 2.80 & III \\
\hline \multirow[t]{5}{*}{ G2 } & 16(G2,G6) & 1.33 & LII & AB5 & 46(AB5,F8) & 2.70 & $\mathbf{V}$ \\
\hline & $17(\mathrm{G} 2, \mathrm{G} 1)$ & 1.50 & XLVII & & 47(AB5,F8) & 1.40 & $\mathrm{~L}$ \\
\hline & $18(\mathrm{G} 2, \mathrm{G} 1)$ & 1.60 & XLIV & & 48(AB5,F9) & 1.63 & XLII \\
\hline & $19(\mathrm{G} 2, \mathrm{G} 1, \mathrm{G} 9)$ & 2.20 & XXII & & 49(AB5,G10) & 1.26 & LV \\
\hline & $20(\mathrm{G} 2, \mathrm{G} 1, \mathrm{~F} 7)$ & 1.83 & XXXIV & & $50(\mathrm{AB} 5, \mathrm{~F} 2)$ & 2.46 & XI \\
\hline \multirow[t]{5}{*}{ F9 } & 21(F9,G8) & 2.83 & II & $\mathrm{AB} 3$ & 51(AB3,G4) & 2.40 & XIII \\
\hline & 22(F9,G8) & 2.16 & $\mathrm{XX}$ & & $52(\mathrm{AB} 3, \mathrm{G} 4)$ & 2.00 & XXV \\
\hline & 23(F8,G1) & 2.60 & VIII & & 53(AB3,G1,F8) & 1.56 & XLV \\
\hline & 24(F9,F7) & 1.53 & XLVII & & $54(\mathrm{AB} 3, \mathrm{~F} 8)$ & 1.10 & LIX \\
\hline & 25(FF9.G4,G8) & 2.36 & XXXX & & $55(\mathrm{AB} 3, \mathrm{G} 1, \mathrm{~F} 8)$ & 1.36 & LI \\
\hline \multirow[t]{5}{*}{ F5 } & 26(F5,G5) & 1.46 & XLVIII & $\mathrm{AB} 7$ & $56(\mathrm{AB} 7, \mathrm{~F} 7)$ & 2.66 & VI \\
\hline & 27(F5,F9) & 1.33 & LIII & & $57(\mathrm{AB} 7, \mathrm{G} 10)$ & 1.70 & XL \\
\hline & 28(F5,F3) & 1.30 & XVII & & $58(\mathrm{AB} 7, \mathrm{~F} 10)$ & 1.86 & XXXII \\
\hline & 29(F5,G1) & 1.73 & XXXVIII & & $59(\mathrm{AB} 7, \mathrm{~F} 10)$ & 2.13 & XXI \\
\hline & 30(F5,G8) & 1.90 & XXXI & & $60(\mathrm{AB} 7, \mathrm{~F} 10)$ & 2.63 & VII \\
\hline
\end{tabular}


Int.J.Curr.Microbiol.App.Sci (2019) 8(2): 2073-2080

\section{Created Designs for Development of Jackets}

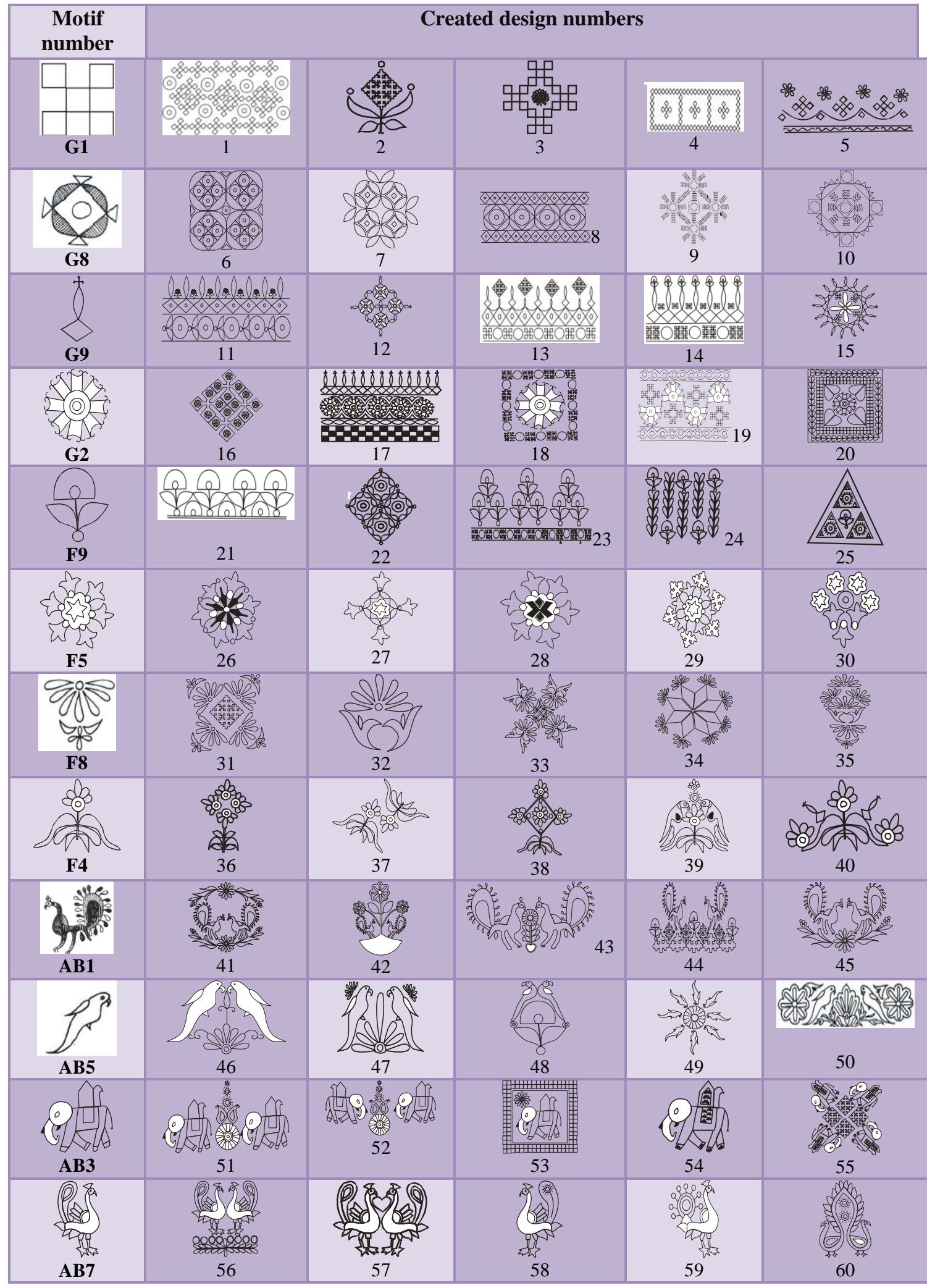


Thus, design number 3, 13, 21, 45 and 46 were selected for design placements. Design numbers 3,13 , and 21 were created by combining geometrical and floral motifs while design number 45 and 46 were created by combining floral and animal $\&$ bird motifs.

Thus, floral designs played an important role in creation of designs for jacket. The results are supported by Athirstam and Thilagam (2014) stated that floral designs are ideal for adding a feminine touch to many items. Floral designs are popular embroidery designs and are available in a range of styles from classic to cotemporary.

In conclusion, animal \& bird and floral motifs were the most commonly used motifs for kathiawar embroidery. Nearly one fourth number of created kathiawar embroidery designs developed by combining geometrical, floral and animal \& birds motifs were highly preferred and half of the created designs were preferred by the experts as the use of CAD technology make the process of designing more efficient and has enhanced the range of designing. Floral and geometrical designs were highly acceptable among consumers for jacket as compare to animal \& bird motifs.

\section{References}

Acharya, P. A. 2017. Innovative traditional kathiawar embroidery on fashion garment. International Journal of Science and Research 6(4): 24592462.

Athirstam, J. and C. Thilagm. 2014. A study on development and evaluation of Indian embroidery in sarees. Multidisciplinary Research Journal of College 1(2): 150-156.

Byadgi, S. A. and S. D. Naik. 2010. Hand embroidery and jamdani patterned Dharwad Sarees: A comparative study; Asian Journal of Home Science 5(2): $1-10$

Garg, R. 2016. To study the modifications and new prospects in kathiawar stitches on cushion cover. Asian Journal of Home Science 11(2): 415424.

Kaur, A. 2015. Embroidery - An embellishment on women's wear. Research Journal of Family, Community and Consumer Sciences 3(9): 4-6.

\section{How to cite this article:}

Pooja, Vivek Singh and Nisha Arya. 2019. Development of Contemporary Kathiawar Embroidery Designs for Jacket. Int.J.Curr.Microbiol.App.Sci. 8(02): 2073-2080. doi: https://doi.org/10.20546/ijcmas.2019.802.240 